\title{
Diet Communication on the Early Silk Road in Ancient China: Multi-Analytical Analysis of Food Remains From the Changle Cemetery
}

\author{
Meng Ren \\ Palace Museum
}

\section{Renfang Wang}

Ningxia Institute of Cultural Relics and Archaeology

Yimin Yang ( $\nabla$ yiminyang@ucas.ac.cn )

University of Chinese Academy of Sciences https://orcid.org/0000-0003-2745-9498

\section{Research Article}

Keywords: Ancient foodstuff, Baked cake, Kebab, Culture communication, Proteomics

Posted Date: January 25th, 2022

DOI: https://doi.org/10.21203/rs.3.rs-1271408/v1

License: (1) This work is licensed under a Creative Commons Attribution 4.0 International License.

Read Full License

Version of Record: A version of this preprint was published at Heritage Science on April 4th, 2022. See the published version at https://doi.org/10.1186/s40494-022-00682-w. 


\begin{abstract}
Characterization of ancient food remains could reflect how people exploited biological resources and interact with different cultures in the past. In this study, Fourier Transform Infrared Spectroscopy (FTIR), starch grain, phytolith, stable isotope analysis and proteomics were adopted to characterize the composition of the food remains including three cereal foodstuffs, some meat strips and a kebab discovered at the Changle Cemetery (202 BC-AD 220), Ningxia, China, a key area on the Silk Road. The results show that the cereal foods were baked cakes, primarily made from foxtail millet (Setaria italica). One cake was simply made of millet grains, the others were more elaborately comprised of millet flour with the addition of barley flour and meat from cattle (Bos taurus) and chicken (Gallus gallus). These findings indicate that grinding and baking technologies, which were considered as the culinary tradition in western Eurasia, had been at latest adopted by the inhabitants in the Ningxia area at that time. The large-scale migration to Ningxia and the opening of the Silk Road during the Han Dynasty gave rise to diet communication and assimilation in this border area. Moreover, the meat strips were identified as dried beef, and the kebab was likely to be made from sheep/goat meat, wherein the latter is the earliest scientific evidence of mutton kebab in ancient China up to our knowledge. The analytical strategy could be widely applied in characterizing ancient visible food remains in order to better understand their preparation methods.
\end{abstract}

\title{
Key words
}

Ancient foodstuff; Baked cake; Kebab; Culture communication; Proteomics

\section{Introduction}

Food production is fundamental to human society, and archaeological foodstuffs can provide straightforward information regarding to ancient diets and food culture. Due to distinctive geographical environments, economic patterns and cultural traditions, different social groups tend to have different characteristics concerning food processing activities. It is widely accepted that roasting/grinding technologies were the primary cooking methods in western Eurasia (the Near East and the Mediterranean), while boiling/steaming were the main methods in eastern Eurasia (China and the Far East), with overlapping food patterns in South Asia[1]. Several

\footnotetext{
* Correspondence: yiminyang@ucas.ac.cn

${ }^{1}$ Department of Conservation Science, Palace Museum, Beijing 100009, China.

2 Ningxia Institute of Cultural Relics and Archaeology, Yinchuan, 750001, China.

${ }^{3}$ Department of Archaeology and Anthropology, University of Chinese Academy of Sciences, Beijing 100049, China.
} 
works have been conducted to investigate the composition and manufacturing of ancient crop foods found in northwest China, which connects central China and western Eurasia. Some ancient cakes excavated from the Subeixi site (500-300 BC) were identified to be made from common millet (Panicum miliaceum) by baking[2]. The desiccated foodstuffs in the Yanghai Tombs (approximately $600 \mathrm{BC}$ ) were cooked dough food made from wheat (Triticum aestivum) and barley (Hordeum spp.)[3]. In addition to plant microfossil methods (starch grain and phytolith analysis), proteomics was also adopted to investigate the cereal food from the Subeixi site and showed that it was a sourdough bread made from barley and broomcorn millet by leavening with baker's yeast and lactic acid bacteria[4]. These previous studies suggest that grinding/baking techniques were widespread among the nomadic people in Xinjiang area, north-western China, at least 2,500 years ago. Also, cereal flour based food has a long history in China, such as the 4,000-year-old noodles discovered from the Lajia site, which were proved to be made from millet flour[5].

Meat was also an important source of food, and the principal domestic animals in ancient China included horses, cattle, sheep/goats, pigs, dogs and chickens[6]. The evidence for consumed animal products has been primarily based on skeletal remains and stable isotope analysis of human bones due to the poor preservation conditions of ancient animals' soft tissues and their products, as well as the restrictions of analytical techniques. Recently, stable isotope analysis[7], lipid analysis[8] and proteomics[4, 9] have been utilized and improved for the identification of organic materials in food remains.

According to Hou Han Shu (Book of Later Han), baked food such as Hu bing had been introduced into central China and became popular among the Han people at least in the Eastern Han Dynasty (AD 25-220)[10]. It was recorded in Shiming (a dictionary that was compiled at the end of the Han period) that Hu bing was the baked wheaten food and sometimes sprinkled with sesame seeds. Recent reresearch on visible food remains, however, has been restricted in the western part of China, especially in the Turpan region, where organic remains are well preserved because of the arid climate. More work is needed in adjacent regions to better understand the introduction of grinding/baking techniques to the eastern region of ancient China. The Ningxia Province is located in the mid-northern part of China in the upper reaches of the Yellow River. The northern minorities have been concentrated in this region since ancient times, and during the Western Han Dynasty (202 BC-9 AD) it became the key area of immigration from central China. In addition to the prosperity of the Silk Road, Ningxia area acted as an important communication centre between the eastern and western parts of ancient China, which lead to the diversity of diet cultures in the indigenous population, and these diet cultures inevitably influenced one another in this region. Some processed food remains, including possible cereal foods, meat strips and kebabs, were unearthed at the Changle Cemetery (Fig.1), Ningxia, which could provide direct evidence for the dietary communication among different populations in the surrounding areas, and its influence on the food culture in central China.

Human diet has become complicated with the development of society, and ancient foods were accordingly more elaborate with a greater diversity of ingredients. 
Therefore, a multi-step analytical procedure is adopted to perform a more comprehensive examination on the archaeological food remains excavated at the Changle Cemetery. In this study, micro-samples were firstly submitted to FTIR analysis to characterize their major constituents, and these preliminary results were used to guide further analyses. The cereal foodstuffs were then analyzed by plant microfossil observation to determine their composition and processing technologies. Stable isotope analysis and proteomics were performed to obtain more detailed component information.

\section{Materials and methods}

\section{Materials}

The Changle Cemetery $\left(37^{\circ} 26^{\prime} 24.8^{\prime \prime} \mathrm{N}, 105^{\circ} 05^{\prime} 43.0^{\prime \prime} \mathrm{E}\right)$ is located $2.5 \mathrm{~km}$ south to the Changle Town in Zhongwei City, Ningxia Province (Fig. 1). From May to November 2012, the field team conducted the fourth archaeological excavation of this site, and 24 tombs were discovered. 15 tombs are medium cave-type graves, whereas the others are small rectangular earthen pit graves. The Changle Cemetery dates back to the Han Dynasty (202 BC-220 AD), when Zhongwei was under the jurisdiction of the Anding Prefecture in the border area. The funeral objects were mostly bronze coins and pottery, and the identified animal bones include pigs, sheep/goat, cattle, a dog, chickens, and other poultry bones. Based on the features of the tombs and funeral objects, the owners were possibly immigrants from central China areas[11].

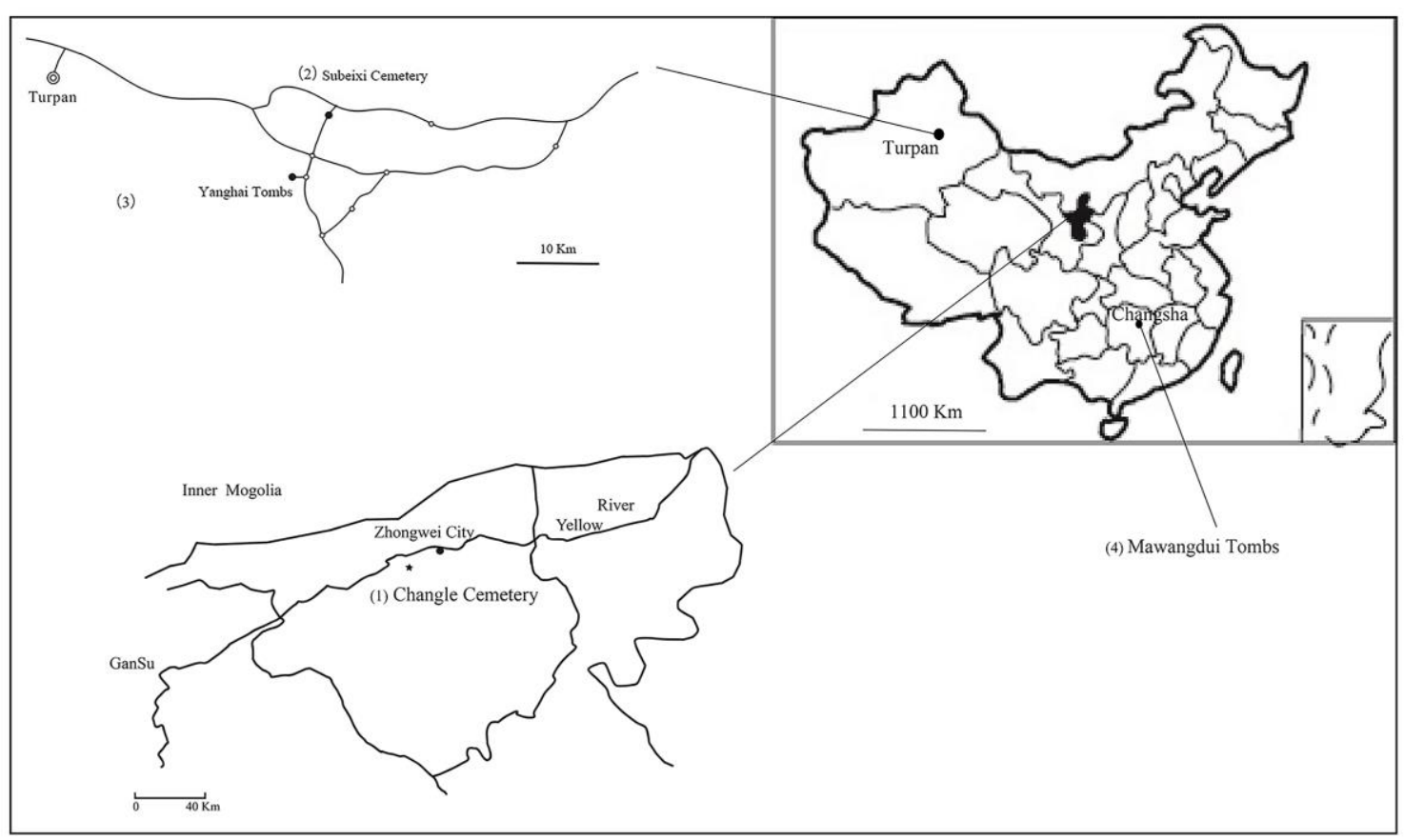

Fig. 1 The location of the Changle Cemetery and other mentioned sites in China.

Some food remains were found in Tomb M17, which is a cave-type grave with sloping tomb-passage. The coffin chamber was rounded by wooden pillars with thick 
planks covered, and the funeral objects contained potteries, wuzhu-coins, woodenware, lacquerware, a wooden house model, a wooden staff statue, and plant seeds. The human body was completely wrapped in the shroud, so physical anthropology examination is not carried out until now. It is worth mentioning that the wooden staff statue was the status symbol of the elder, indicating that the owner was a venerable old man.
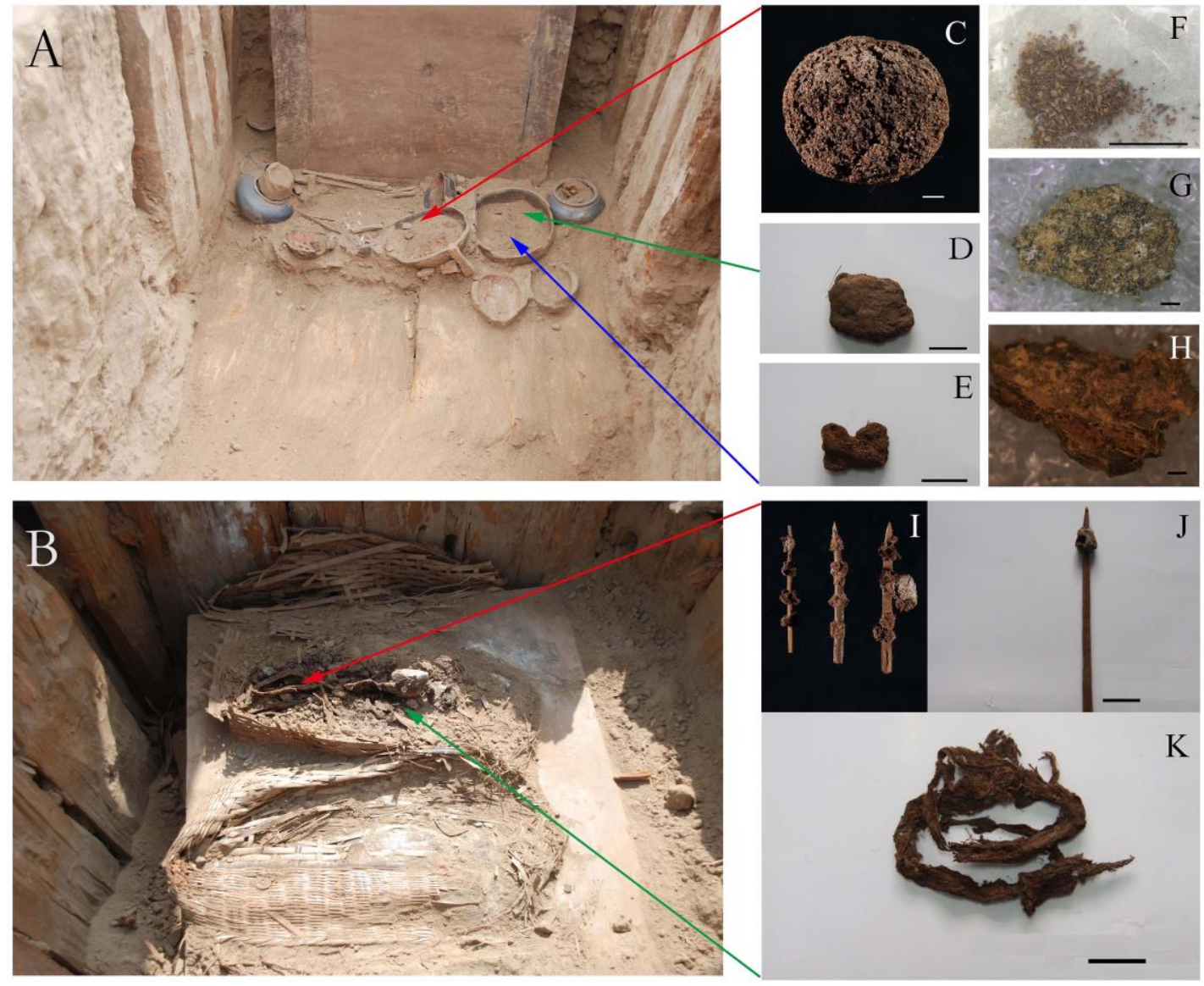

Fig. 2 The archaeological food remains in Tomb M17: (A, B) the position of the food remains when excavated, (C-E) cereal 1-3, (F) grains fallen out from cereal 1, (G, H) cross-section images of cereal 2 and cereal 3, respectively (I) the archaeological kebabs in Tomb M17, (J) the kebab (meat 1) analyzed in this study, and $(\mathrm{K})$ meat 2 . Scale bars: $500 \mu \mathrm{m}$ for $(\mathrm{G}, \mathrm{H})$, and $2 \mathrm{~cm}$ for the others.

Table 1. Description of the archaeological food remains.

\begin{tabular}{ccc}
\hline Archaeological code & Sample & Description \\
\hline 12SCM17-5 & cereal 1 & Hemispherical cake mainly made from loose grains, brown in color. \\
\hline 12SCM17-4-1 & cereal 2 & Flat cake made from cereal flour, brown in color. \\
\hline 12SCM17-4-2 & cereal 3 & Irregularly shaped cake made from cereal flour, brown in color. \\
\hline SCM17-14 & meat 1 & Kebab, a small piece of meat pierced on a wooden skewer. \\
\hline SCM17-5 & meat 2 & Dried meat strips. \\
\hline
\end{tabular}

Five food samples were investigated in this study, including three possible cereal food remains and two meat remains (Fig. 2 and Table 1). The cereal foodstuffs were 
found in two lacquerwares placed on the ground in front of the coffin. Specifically, cereal 1 was placed in one lacquer bowl, and cereal 2 and cereal 3 were in another one. The meat remains were found in a bamboo basket on the coffin lid. In addition, modern foxtail millet (Setaria italica) was also selected for comparison studies.

Optical observation. The cross-sections of the archaeological food samples were observed under a VHX-600 digital microscope (Keyence, Japan) and photographed at $50 \times$ magnification .

FTIR. Infrared spectra were recorded using a Fourier transform infrared spectrometer (Nicolet 6700, USA). Samples were analyzed as $\mathrm{KBr}$ pellets in transmission mode. Spectra were acquired over the range of $4000-400 \mathrm{~cm}^{-1}$, with a resolution of $4 \mathrm{~cm}^{-1}, 32$ scans per spectrum. The software OMNIC 8.0 was applied to deal with data.

Plant microfossil analysis. (1) Starch grain analysis. A little material was scraped by a clean lancet into a $1.5 \mathrm{~mL}$ Eppendorf tube and soaked in $1 \mathrm{~mL}$ deionized water for several hours. After shaking, the slide was made using 1:1 glycerin/water. Then slides were viewed and photographed in both transmitted light and polarized light under $500 \times$ magnifications. (2) Phytolith analysis. Each sample was placed in a baker with $5 \mathrm{~mL}$ nitric acid, and stirred occasionally until the reaction ceased. Then the beaker was heated at $70^{\circ} \mathrm{C}$ for $3 \mathrm{~h}$, and a small amount of nitric acid was added several times during the period. The solutions were centrifuged at $3,000 \mathrm{~g}$ for $5 \mathrm{~min}$, decanted and rinsed twice with deionized water. After dry at room temperature, the phytolith sediments were mounted onto microscopic slides in Canada balsam for photomicrography. Slides were viewed under $500 \times$ magnifications.

Cooking experiments. In order to figure out the cooking technique of the ancient cake samples, modern foxtail millet was subjected to three processing methods: boiling, baking, and steaming. (1) The cereal was ground, mixed with water and kneaded into noodles, then put in boiling water for about $5 \mathrm{~min}$. (2) The ground cereal was kneaded to dough and steamed for $10 \mathrm{~min}$. (3) The ground cereal was kneaded to dough and baked at $200^{\circ} \mathrm{C}$ for $20 \mathrm{~min}$. After being cooked, each sample was treated in the same way as the archaeological samples for starch grain analysis.

Stable Carbon and Nitrogen isotope analysis. Each sample portion was placed in a beaker with $0.1 \mathrm{M}$ hydrochloric acid to remove carbonates. Then the sample was washed to neutrality, freeze-dried, and ground into fine powder. Stable isotope analysis was performed by an IsoPrime 100 IRMS (Elementar, UK) mass spectrometer coupled with an Elementar Vario (Elementar, UK). Isotope ratios $\left({ }^{13} \mathrm{C} /{ }^{12} \mathrm{C}\right.$ or $\left.{ }^{15} \mathrm{~N} /{ }^{14} \mathrm{~N}\right)$ are expressed as $\delta$ in per mil (\%) relative to the internationally defined standards for carbon (Vienna Pee Dee Belemnite, VPDB) and nitrogen (Ambient Inhalable Reservoir, AIR). The measurement errors were less than $\pm 0.2 \%$ for both $\delta^{13} \mathrm{C}$ and $\delta^{15} \mathrm{~N}$ values. 
Proteomic analysis. For each food remain, a subsample of about $10 \mathrm{mg}$ was suspended in $100 \mu \mathrm{L}$ of extracting solution (Tris- $\mathrm{HCl}, \mathrm{pH} 8.0,10 \mathrm{Mm}$ dithiothreitol, $10 \%$ sodium dodecylsulfate and $0.0025 \%$ bromophenol blue). The mixture was subjected to ultrasonic baths $(3 \times 15 \mathrm{~min})$ and incubated for $1 \mathrm{~h}$ at $56^{\circ} \mathrm{C}$. Then the sample was sonicated again for $15 \mathrm{~min}$ and centrifuged for $15 \mathrm{~min}$ at $12,000 \mathrm{~g}$.

$5 \mu \mathrm{L}$ of glycerol was added to $45 \mu \mathrm{L}$ of the supernatant, heated at $95^{\circ} \mathrm{C}$ for $5 \mathrm{~min}$. After cooling to the room temperature, the extracting solution was loaded onto the gel (SDS-PAGE, sodium dodecyl sulfate polyacrylamide gel electrophoresis) with $25 \mu \mathrm{L}$ each well. The electrophoresis apparatus was connected to a $200 \mathrm{~V}$ power. The gel with sample was immersed in the staining solution $(0.25 \%$ Coomassie Blue w/v, $50 \%$ ethanol, $10 \%$ acetic acid) and incubated in the microwave oven at medium-low heat for $45 \mathrm{~s}$ followed by slowly shaking for $10 \mathrm{~min}$. The gel was washed with water for several times, and destained in the solution (25\% ethanol, $8 \%$ acetic acid) until protein bands were visible.

The gel with protein band was cut into small particles and washed by distilled water three times. Then the gel particles were destained with $50 \%$ acetonitrile $/ 25 \mathrm{mM}$ $\mathrm{NH}_{4} \mathrm{HCO}_{3}$ and alkylated in the dark with $50 \mathrm{mM}$ iodoacetamide for $30 \mathrm{~min}$. the gel pieces were then washed with $25 \mathrm{mM} \mathrm{NH}_{4} \mathrm{HCO}_{3}$ buffer twice and immersed in $12.5 \mathrm{ng} / \mu \mathrm{L}$ trypsin solutions. The digestion was incubated in the microwave oven at $850 \mathrm{~W}$ for $1 \mathrm{~min}$.

The digested sample was re-dissolved in $0.1 \%$ formic acid (buffer A), and analyzed by ChromXP nano LC column $(75 \mu \mathrm{m} \times 15 \mathrm{~cm}$, ChromXP C18-CL $3 \mu \mathrm{m} 120 \AA)$ from Eksigent. The gradient ran at $300 \mathrm{~nL} / \mathrm{min}$ from $5 \%$ to $80 \%$ buffer B $(0.1 \%$ formic acid in acetonitrile) over $1 \mathrm{~h}$. The parameters of Triple TOF $5600+$ mass spectrometer: curtain gas: 30 ; GS1: 4 ; ion spray voltage: $2.3 \mathrm{kV}$; TOF MS spectrum acquisition time: $0.25 \mathrm{~s}(\mathrm{~m} / \mathrm{z}$ 350-1250); a rolling collision energy voltage was used for CID fragmentation MS/MS scans; IDA number: 30; MS/MS spectra acquisition time: $0.1 \mathrm{~s}$ (m/z 100-1500); dynamic exclusion time: $25 \mathrm{~s}$.

The MS/MS spectra were searched against the NCBInr database (released 201604; 87,376,087 sequences; 32,052,401,578 residues) by Mascot software version 2.4.1 (Matrix Science, UK). Trypsin was selected as the proteolytic enzyme and two missed cleavages were allowed. Carbamidomethylation (C) was selected as fixed modification. Acetyl (Protein N-term), deamidation (NQ), Gln->pyro-Glu (N-term Q) and oxidation $(\mathrm{M})$ were selected as variable modifications. A peptide tolerance of 10 $\mathrm{ppm}$ and a product ion tolerance of $0.05 \mathrm{Da}$ were used in the searches and the peptides were filtered with significance threshold $p<0.05$ and ions score cut-off 25 . In order to check the species-specificity of the sequences, each peptide sequence was submitted to the protein Basic Local Alignment Search Tool (BLASTp tool) in the NCBInr database available on the website of National Center for Biotechnology Information (http://blast.ncbi.nlm.nih.gov/Blast.cgi).

\section{Results}

\section{FTIR analysis}


The three cereal samples show similar infrared spectra with the presence of starch (Fig. 3A). The peak at approximately $1154 \mathrm{~cm}^{-1}$ was assigned to $\mathrm{C}-\mathrm{O}$ stretching region, the peak at $1080 \mathrm{~cm}^{-1}$ was assigned to $\mathrm{C}-\mathrm{O}-\mathrm{H}$ bending vibration region, and the peak at $1030 \mathrm{~cm}^{-1}$ was assigned to $\mathrm{C}-\mathrm{O}$ bending region[12]. This pattern of absorption peaks was characteristic of the starch moiety and indicated that they were starch-rich foodstuffs. The peak around $1630 \mathrm{~cm}^{-1}$ was attributed to $\mathrm{C}=\mathrm{C}$ stretching frequency, which suggests that these cereal foods might have been processed by heating[13]. The bands at approximately 1650 and $1540 \mathrm{~cm}^{-1}$ in the infrared spectra (Fig. 3B) obtained from the two meat samples were characteristic to amide groups $(-\mathrm{N}(\mathrm{H})-\mathrm{C}=\mathrm{O}-)[14]$, indicating proteinous products.

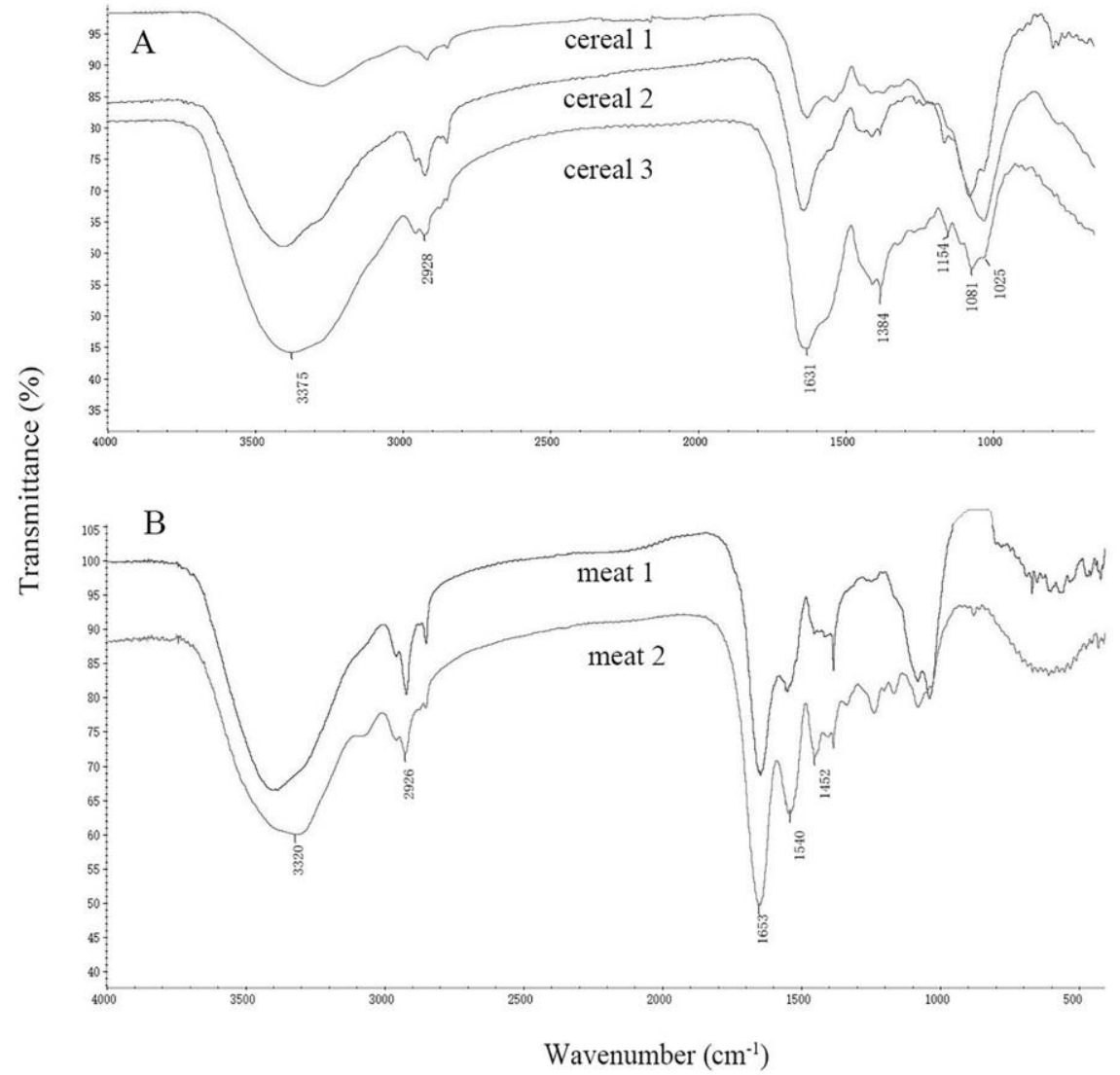

Fig. 3 FTIR spectra of the archaeological food remains: (A) cereal samples and (B) meat samples.

\section{Phytolith analysis}

Compared with literature data[15], the phytoliths in the archaeological cereal samples (Fig. 4) showed the characteristics of Setaria italica. In detail, there are regularly arranged papillae on the surface of the sample, the epidermal long cell walls are $\Omega$-undulated (i.e., the undulations are rounded, wider towards the apex and narrower at the base), and the ending structure of the epidermal long cell is a "cross wavy type" (i.e., the dendriform epidermal long cell endings join others in a wavy pattern). Thus, we deduced that the main component of three cereal food remains was foxtail millet. 

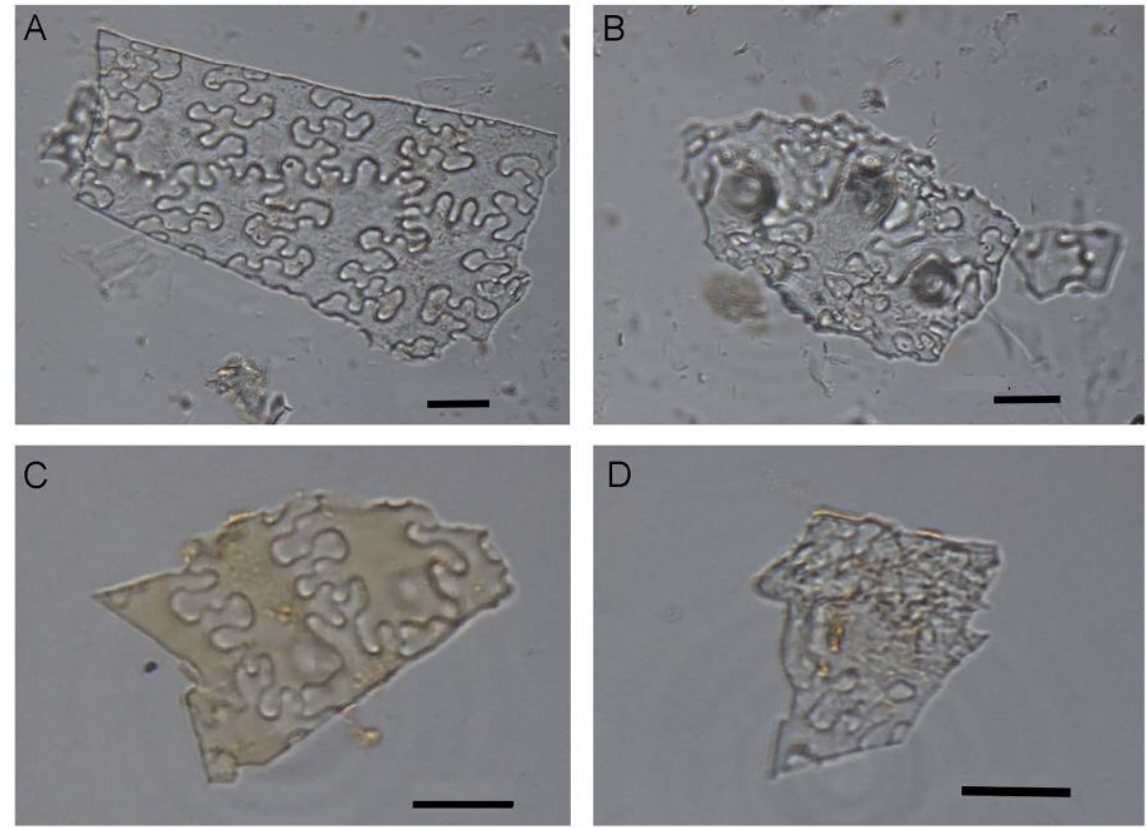

Fig. 4 The phytoliths from the archaeological cereal samples: (A, B) cereal 1, (C) cereal 2, and (D) cereal 3. Scale bars: $20 \mu \mathrm{m}$.

\section{Starch grain analysis and cooking experiments}

Most of the starch grains that were observed in the archaeological cereal samples were damaged and lacked morphological characteristics (Fig. 5). The starch grains were mainly brownish and were pasted in clusters. The starch grains were swollen and partially gelatinized, with indistinct or an otherwise loss of cross-extinction properties under a polarized microscope. Previous studies have shown that cooking can lead to significant morphological changes in starch grains[16, 17]. In terms of the phytolith analysis, modern foxtail millet was used as a reference to examine the cooking process of the archaeological samples. 

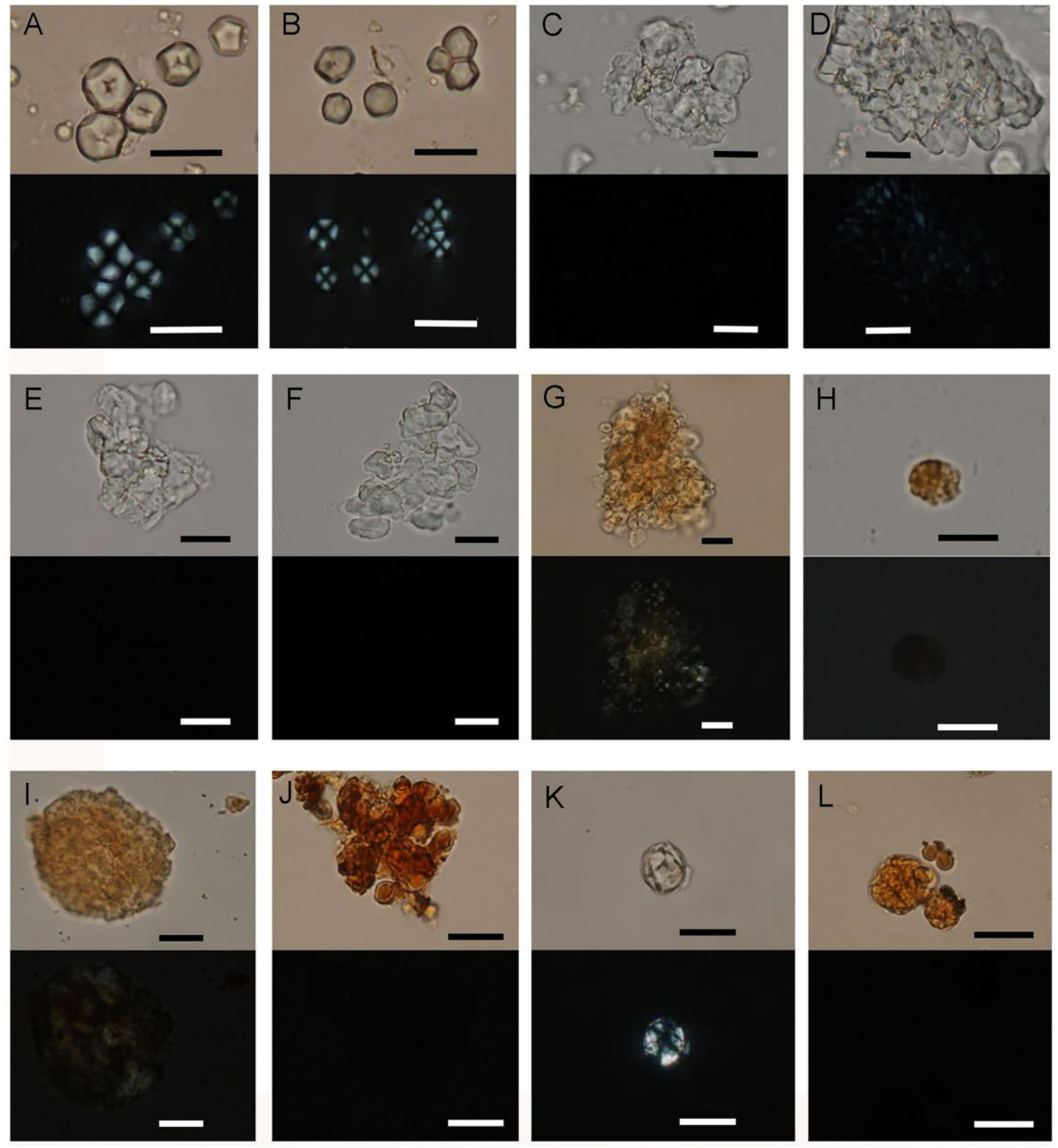

Fig. 5 The morphology of starch grains from modern foxtail millet (S. italica) and archaeological cereal samples: (A, B) uncooked modern S. italic, (C, D) modern boiled S. italic, (E, F) modern steamed S. italic, (G, H) modern baked S. italic, (I) cereal 1, (J) cereal 2, and (K, L) cereal 3. The upper row of photographs showing starch grains viewed under transmitted light, and the lower row showing the corresponding grains under polarized light. Scale bars: $20 \mu \mathrm{m}$.

The starch grains from modern foxtail millet that were obtained through different cooking methods are shown in Figure 5. Boiling caused swelling, collapse and gelatinization of the starch grains, with an almost complete loss of the cross-extinction. Meanwhile, the starch grains were pasted together and had vague outlines (Fig. 5C and D). Steaming, similar to boiling, caused extensive swelling and gelatinization of the starch granules, with an almost total loss of the cross-extinction. Most of the steamed starch grains were completely damaged, and the partly-damaged grains became puckered, curved and irregularly-shaped (Fig. 5E and F). Regarding 
baking, the starch grains became pasted in clusters, swollen and gelatinized, and exhibited damaged cross-extinction or sometimes a loss of extinction (Fig. 5G and $\mathrm{H}$ ). In addition, the baked granules were brown, which was likely caused by the Millard reaction, which is a type of non-enzymatic browning between amino acids and reducing sugars[18]. This phenomenon of colour change was also found in the baking experiments of wheat flour[17], but not observed in other cooking methods. Accordingly, the appearance of the archaeological starch grains (Fig. 5I-L) exhibited a close resemblance to that of baked samples, which implies that three cereal remains were cooked by baking.

\section{Stable Carbon and Nitrogen isotope analysis}

There are essentially three types of plants in the natural world according to different photosynthetic pathways, namely, $\mathrm{C}_{3}, \mathrm{C}_{4}$, and CAM plants. The variation in $\delta^{13} \mathrm{C}$ among these plants is significant, with $\mathrm{C}_{3}$ plants having the lowest $\delta^{13} \mathrm{C}(\sim-26.5 \%)$, $\mathrm{C}_{4}$ plants having the highest $\delta^{13} \mathrm{C}(\sim-12.5 \%)$, and CAM plants having a mixed isotopic composition[19, 20]. Foxtail millet (S. italica) and common millet ( $P$. miliaceum) were the major crops in ancient northern China, and all are $\mathrm{C}_{4}$ plants[21, 22]. The fractionation of $\delta^{15} \mathrm{~N}$ is dominated by a trophic-level effect, which leads to an approximate 3 5\% increase associated with the ascending step in the food chain[23-26].

Table 2. The results of $\delta^{13} \mathrm{C}$ and $\delta^{15} \mathrm{~N}$ analyses of the archaeological food samples.

\begin{tabular}{cccccc}
\hline Sample & $\boldsymbol{\delta}^{\mathbf{1 3}} \mathbf{C}(\mathbf{\% o})$ & $\boldsymbol{\delta}^{\mathbf{1 5}} \mathbf{N}(\mathbf{\% o})$ & Carbon content (\%) & Nitrogen content (\%) & Atomic C/N \\
\hline cereal 1 & -11.55 & 6.03 & 47.96 & 4.41 & 12.68 \\
\hline cereal 2 & -11.63 & 11.00 & 44.48 & 5.95 & 8.80 \\
\hline cereal 3 & -12.09 & 10.53 & 40.53 & 4.59 & 10.30 \\
\hline meat 2 & -15.52 & 11.75 & 46.59 & 15.24 & 3.57 \\
\hline
\end{tabular}

Table 2 shows the $\delta^{13} \mathrm{C}$ and $\delta^{15} \mathrm{~N}$ values of the food remains. The $\delta^{13} \mathrm{C}$ values of the cereal food samples range from $-12.09 \%$ to $-11.55 \%$, which indicates that they predominately comprised of $\mathrm{C}_{4}$ plants and are consistent with the results of the phytolith analysis. The meat sample had a lower $\delta^{13} \mathrm{C}$ value, which indicated some input of $\mathrm{C}_{3}$ plants in the animal's diet. The $\delta^{15} \mathrm{~N}$ values of cereal 2 and cereal 3 were higher than that of cereal 1 , and similar to the $\delta^{15} \mathrm{~N}$ value of the meat sample, which implies the addition of animal proteins.

\section{Proteomic analysis}

Proteomic identification was then performed to characterize the nature and species of the protein materials in these foodstuffs. The LC/MS/MS results listed in Table S1 show that collagen and actin were the major proteins that were identified in the meat samples, besides the disregarded human background proteins. Notably, the proteins from plant starch and animal meat were simultaneously detected in cereals 2 and cereal 3, including amylase, starch synthase, myosin, actin, muscle auxiliary protein, collagen and others. Amylase is an enzyme for starch and glycogen hydrolysis; 
$\beta$-amylase is particularly present in higher plants and does not exist in mammals[27]. Collagen is the main component of connective tissue that is mostly found in tendons, ligaments and skin, and collagen type I (collagen $\alpha 1$ type I and collagen $\alpha 2$ type I) is the most abundant collagen in vertebrates[28]. Actin is a structural protein of microfilaments and an important cytoskeleton protein, which is widespread in muscle tissue and cells[29, 30]. Myosin is the main unit of myofibrils and is a component of cytoskeleton[31]. The proteomics results further confirm that animal meat was added to cereal 2 and cereal 3, which is consistent with the nitrogen isotope results.

According to the results of BLAST searches, the specific peptides of foxtail millet ( $S$. italica) were identified in both cereal samples. The sequences in $\beta$-amylase specific to barley ( $H$. vulgare) were also present in cereal 3, while the barley phytoliths were not found. This lack of barley phytoliths is probably due to that only a small amount of barley flour was added in consideration of the results of carbon isotope analysis. Furthermore, the specific sequences of myosin were assigned to cattle (Bos taurus) and chicken (Gallus gallus) in cereal 2, which is in accordance with the animal bones that were excavated at Changle Cemetery[11]. In cereal 3, the bovine-specific peptides were equally present for cattle (Bos taurus), bison (Bison bison bison), yak (Bos mutus), water buffalo (Bubalus bubalis), and zebu (Bos indicus). Zooarchaeological data show that other species of bovine bones have not been found in this region except for cattle. Also, the climate and geographic conditions at Changle area are not suitable for water buffalo or yak to live in. Therefore, the animal proteins in cereal 3 probably originated from cattle. Similarly, cattle are also the most likely origin of the bovine-specific peptides in meat 2 , and considering the its toughness, meat 2 should come from beef that was rich in tendons. Regarding meat 1, specific peptides come from goats (Capra hircus), sheep (Ovis aries), European mouflon (Ovis aries musimon) and Tibetan antelope (Pantholops hodgsonii). Given the specific geographical environment and zooarchaeological results, meat 1 should come from a sheep/goat, and it is the earliest mutton kebab identified in China up to our knowledge.

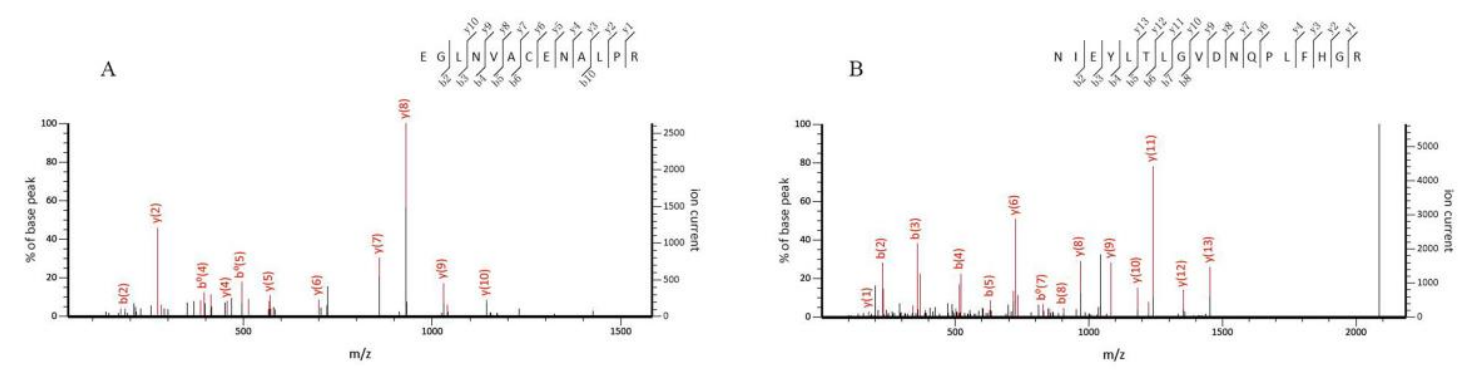

Fig. $6 \mathrm{MS} / \mathrm{MS}$ spectra of two $H$. vulgare specific peptide sequences from beta-amylase identified in cereal 3: (A) EGLNVACENALPR and (B) NIEYLTLGVDNQPLFHGR.

\section{Discussion}

The custom of extravagant consumption in burial ceremonies was prevalent during the Han Dynasty; foodstuffs were one of the typical funeral objects and were commonly found in the Han Tombs[32]. For instance, large amounts of elaborate food 
remains placed in different dinner-wares were excavated from the Mawangdui Han Tombs (193-177 BC) in Changsha (Fig. 1), including various cereals, fruit, cakes, kebabs and other meats $[33,34]$. In our study, the specially prepared foods exhumed from Tomb M17 in the Changle Cemetery were placed in certain positions, with cakes placed in front of the coffin, and kebabs and meat strips on the coffin lid. It is likely that they were served as the offerings to the dead at the funeral for higher spiritual enjoyment[35].

Based on phytolith and proteomics analyses, foxtail millet and barley have been identified in the cereal remains. They were made into cakes using different processes: cereal 1 was directly made from millet grains, while the other two samples were made from cereal flour. The traditional processing techniques utilized for millet crops and wheat/barley were different since the Neolithic time. Foxtail millet has been cultivated in China for at least 8,000 years and is usually consumed in grains with boiling or steaming. While wheat and barley were domesticated in western Asia and spread eastwards to Ningxia area through the Hexi Corridor approximately 4,000 years ago; they were often ground into flour for baking[36-38]. During the Han Dynasty, wheat, barley, foxtail millet and common millet were all staple crops in northwest China. However, because of the low effectiveness of milling technology before the Eastern Han Dynasty, millet was easier to process into flour than wheat or barley, and wheaten food was not popular in ancient China at that time[39]. The results in this study also show that millet was the principal flour food.

Cooking experiments suggest that these cakes were all cooked by baking, which was the popular way of preparing food in western Eurasia [1, 40]. The culinary tradition in eastern China should have been boiling/steaming, which is also reflected in archaeological artefacts such as the water heating pot " $F u$ " and steamer "Zeng". As mentioned earlier, baked cake has also been a traditional food in Xinjiang area for ages. The present study indicates that this dietary custom may have spread eastwards into Ningxia area and that the indigenous people also mastered grinding/baking technologies. It is noteworthy that cereal 1 , which was the baked cake made from millet grains, represents the integration of diet cultures, with the uptake of baking technique and the maintaining of grain-consuming tradition of millet. The similar-looking cake was also found in the Mawangdui Tomb M1 in south-central China[33], which would seem to suggest that the cereal grain based cake was relatively a popular food in the Han Dynasty.

In addition to the cooking style, diet structure was also different between different peoples. Generally, cereal was the staple food for the Han people in central China, while meat and cheese occupied a large portion in the diet of the Hu people (ancient nomadic people). The results of stable isotope and proteomics analyses show that chicken and/or cattle meat were also added to some of the cakes. The addition of meat could improve the flavour and nutrition of cereals but has been rarely reported in previous studies. This type of cake resembling the ancient food $H u$ bing. According to the ancient Chinese agricultural encyclopaedia Qi Min Yao Shu, which was written about 1,500 years ago, $H u$ bing was basically made from flour, mixed with animal fat and minced meat and baked in an oven-like hearth. The findings of our study would 
stand as the direct evidence of this kind of food in ancient China. Since Hu bing was often made from wheaten flour, cakes discovered at Changle Cemetery, which were mainly made from millet flour, might be the imitations of $\mathrm{Hu}$ bing.

Besides the cattle and chicken meat added in the cake samples, some dried beef and a mutton kebab were also recognized in this study, which indicates a diversity of meat sources. Although kebab is also a traditional $\mathrm{Hu}$ food, the scenes of roasting skewered meat were frequently depicted in cooking and banqueting images in the Han tombs of the upper echelons[41], and more roasting tools such as grills were found during this period[42, 43]. It can be reflected that kebab has also become popular in central China since the Han Dynasty.

Prior to the Han Dynasty, Ningxia area was the settlement for the nomadic people who led a pastoral life[44]. The Han people from inland regions began to migrate into this area during the Western Han period, and promoted the local agricultural economy[11, 45]. This mobility also facilitated the communication among different populations and their food cultures. In this study, the migrated Han people at Changle Cemetery appear to have maintained some inland dietary characteristics, such as eating cereal grains directly. Concurrently, the dietary traits of the indigenous Hu people, such as consuming large amounts of meat and the baking/roasting of foodstuffs were also present, which suggests that their diet was also significantly impacted by the Hu customs. This cultural communication between the East and West was further accelerated by the opening of the Silk Road and has continuously promoted the richness of Chinese food culture.

\section{Conclusions}

In the present study, we analyzed the food remains excavated from the Changle Cemetery in Ningxia, and we found that the cereal foods were baked cakes, with animal meat added to some flour foodstuffs; and the meat foods include beef strips and a mutton kebab. These findings suggest that the migrated Han people in Ningxia area have adopted some cooking technologies of the Hu people such as baking and grinding, and transformed them to suit their own ingredients and tastes. This research has promoted our understanding on the dietary customs, food culture and burial rituals in this border area during the Han Dynasty. As an important centre along the Silk Road and a key region of migration, Ningxia played an important role in the constant exchange and integration of diverse cultures. We further suggest that the multi-analytical approach, which could provide more comprehensive chemical composition and processing techniques, is of primary importance for the characterisation of complex food remains.

\section{Supplementary material}

Supplementary material Table S1. Identified proteins and specific peptides in the archaeological food remains. 


\section{Declarations}

\section{Availability of data and materials}

All data generated or analysed during this study are included in this published article and its supplementary information files.

\section{Competing interests}

The authors declare that they have no competing interests.

\section{Funding}

This study was supported by the grants from MOE (Ministry of Education in China) Project of Humanities and Social Sciences (No. 17YJAZH107), National Natural Science Foundation of China (42072217), and Fundamental Research Funds for the Central Universities.

\section{Authors' contributions}

MR and YY designed the research; RFW provided archaeological samples and background; MR performed analyses; MR and YY analysed data; and all authors helped drafting/revising the manuscript.

\section{Acknowledgements}

We would like to thank Dr. Huiyun Rao of Key Laboratory of Vertebrate Evolution and Human Origins, Institute of Vertebrate Paleontology and Paleoanthropology, Chinese Academy of Sciences, for her support with Proteomic analysis in this research.

\section{References}

1. Fuller DQ, Rowlands M. Ingestion and food technologies: maintaining differences over the long-term in West, South and East Asia. In: Bennet J, Sherratt S, Wilkinson TC, editors. Interweaving worlds: systematic interactions in Eurasia, 7th to the 1st millennia BC, Essays from a conference in memory of Professor Andrew Sherratt. Oxford: Oxbow Books; 2011. p. 37-60.

2. Gong YW, Yang YM, Ferguson DK, Tao DW, Li WY, Wang CS, et al. Investigation of ancient noodles, cakes, and millet at the Subeixi Site, Xinjiang, China. Journal of Archaeological Science. 2011;38(2):470-9. doi: http://dx.doi.org/10.1016/j.jas.2010.10.006.

3. Zheng HP, Jiang HE, Zhang YB, Lü EG, Yang YM, Wang CS. Early Processed Triticeae Food Remains in The Yanghai Tombs, Xinjiang, China. Archaeometry. 2015;57(2):378-91. doi: 10.1111/arcm.12110.

4. Shevchenko A, Yang YM, Knaust A, Thomas H, Jiang HE, Lu EG, et al. Proteomics identifies the composition and manufacturing recipe of the 2500-year old sourdough bread from Subeixi cemetery in China. Journal of Proteomics. 2014;105:363-71. doi: http://dx.doi.org/10.1016/j.jprot.2013.11.016.

5. Lu HY, Yang XY, Ye ML, Liu KB, Xia ZK, Ren XY, et al. Culinary archaeology: Millet noodles in Late Neolithic China. Nature. 2005;437(7061):967-8.

6. Yuan J. Zooarchaeological study on the domestic animals in ancient China (in Chinese with English abstract). Quaternary Sciences. 2010;30(2):298-306.

7. Yang YM, Jin S, Xie YT, Huang WC, Wang CS. Residue analysis of the bronze Gui excavated from Peng nation in Jiang county, Shanxi Province, China (in Chinese with English abstract). Huaxia Archaeology. 2012;3(67-71).

8. Craig OE, Saul H, Lucquin A, Nishida Y, Tache K, Clarke L, et al. Earliest evidence for the use of 
pottery. Nature. 2013;496(7445):351-4. doi: 10.1038/nature12109

9. Liang YM, Yang YM, Idriss, Li WY, X.M. L, C.S. W. Proteomic analysis of grass basket residues excavated from XiaoHe graveyard (in Chinese with English abstract). Sciences of Conservation and Archaeology. 2012;24(4):81-5.

10. Wang RX. The Spread of Wheat: Seen from the Establishment of Chinese Traditional Cake Food Technique. Archeology, religion and history on the Silk Road. Beijing: Cultural Relics Press; 2011. p. $137-45$.

11. Wang RF, Chen XH. 2012-year archaeological excavation of Han period tombs at Changle in Zhongwei, Ningxia (in Chinese with English abstract). Major archaeological discoveries in China in 2012. Beijing: Cultural Relic Press; 2013.

12. Wu JG. Technology and application of the Fourier transform infrared spectroscopy (in Chinese). Beijing: Scientific and Technical Documentation Press; 1994.

13. Oudemans TFM, Boon JJ, Botto RE. FTIR AND SOLID-STATE ${ }^{13} \mathrm{C}$ CP/MAS NMR SPECTROSCOPY OF CHARRED AND NON-CHARRED SOLID ORGANIC RESIDUES PRESERVED IN ROMAN IRON AGE VESSELS FROM THE NETHERLANDS. Archaeometry. 2007;49(3):571-294. doi: 10.1111/j.1475-4754.2007.00321.x.

14. Derrick MR, Stulik D, Landry JM. Infrared Spectroscopy in Conservation Science. Getty Publications; 1999.

15. Lu HY, Zhang JP, Wu NQ, Liu KB, Xu DK, Li Q. Phytoliths Analysis for the Discrimination of Foxtail Millet (Setaria italica) and Common Millet (Panicum miliaceum). PLOS ONE. 2009;4(2):e4448. doi: 10.1371/journal.pone.0004448.

16. Crowther A. The differential survival of native starch during cooking and implications for archaeological analyses: a review. Archaeological and Anthropological Sciences. 2012;4(3):221-35. doi: 10.1007/s12520-012-0097-0.

17. Dai J, Yang YM, Wang B, C.S. W, H.E. J. Changes in wheat starch grains using different cooking methods: Insights into ancient food processing techniques. Chinese Science Bulletin. 2013;58(Suppl I):82-9.

18. Fu L, Li TG. Reviews on Maillard reaction (in Chinese with English abstract). Food Science and Technology. 2006;31(12):9-11.

19. Marino BD, McElroy MB. Isotopic composition of atmospheric $\mathrm{CO}_{2}$ inferred from carbon in $\mathrm{C}_{4}$ plant cellulose. Nature. 1991;349(6305):127-31.

20. Van der Merwe NJ. Carbon Isotopes, Photosynthesis, and Archaeology: Different pathways of photosynthesis cause characteristic changes in carbon isotope ratios that make possible the study of prehistoric human diets. American Scientist. 1982;70(6):596-606.

21. An CB, Dong WM, Chen YF, Li H, Shi C, Wang W, et al. Stable isotopic investigations of modern and charred foxtail millet and the implications for environmental archaeological reconstruction in the western Chinese Loess Plateau. Quaternary Research. 2015;84(1):144-9. doi: http://dx.doi.org/10.1016/j.yqres.2015.04.004.

22. An CB, Dong WM, Li H, Zhang PY, Zhao YT, Zhao XY, et al. Variability of the stable carbon isotope ratio in modern and archaeological millets: evidence from northern China. Journal of Archaeological Science. 2015;53:316-22. doi: http://dx.doi.org/10.1016/j.jas.2014.11.001.

23. Deniro MJ, Epstein S. Influence of diet on the distribution of nitrogen isotopes in animals. Geochimica et Cosmochimica Actar 1981;45(3):341-51. doi: http://dx.doi.org/10.1016/0016-7037(81)90244-1.

24. Ambrose SH. Effects of diet, climate and physiology on nitrogen isotope abundances in terrestrial foodwebs. Journal of Archaeological Science. 1991;18(3):293-317. doi: http://dx.doi.org/10.1016/0305-4403(91)90067-Y.

25. Hedges REM, Reynard LM. Nitrogen isotopes and the trophic level of humans in archaeology. Journal of Archaeological Science. 2007;34(8):1240-51. doi: http://dx.doi.org/10.1016/j.jas.2006.10.015.

26. Reitsema LJ. Beyond diet reconstruction: Stable isotope applications to human physiology, health, and nutrition. American Journal of Human Biology. 2013;25(4):445-56. doi: 10.1002/ajhb.22398.

27. Kang ML. Starch enzymes and their hydrolyzing styles (in Chinese). Food Engineering. 2008;3:11-4.

28. Sherman VR, Yang W, Meyers MA. The materials science of collagen. Journal of the Mechanical Behavior of Biomedical Materials. 2015;52:22-50. doi: http://dx.doi.org/10.1016/j.jmbbm.2015.05.023. 29. Chen M, Li AY. Research Progress of the Actin, Actin-binding Protein and Cell Movement (in Chinese). Life Sciences. 1997;9:1-5.

30. Kong BH, Xiong YL. Properties and roles of regulatory and cytoskeletal proteins in muscle (in Chinese). Science and Technology of Food Industry. 2011;32:439-42. 
31. Li DY, Ren WJ. Influence of exercise on the structure and function of myosin (in Chinese). Journal of Clinical Rehabilitative Tissue Engineering Research. 2007;11:6458-64.

32. Li RS. Funeral Custom of Han Dynasty (in Chinese). Shenyang: Shenyang Publishing House; 2003.

33. Yu B. Antiques from Mawangdui Tomb and Dietary Culture of Han Dynasty (in Chinese). Collectors. 2010;12:35-42.

34. HPM (Hubei Provincial Museum), IA CASS (Institute of Archaeology Chinese Academy of Social Sciences) Report on the excavation of the Mawangdui Tomb M1 in Changsha (in Chinese). Beijing: Cultural Relics Press; 1972.

35. Zhou LG. Obscuring the Line between the Living and the Dead: Mortuary Activities inside the Grave Chambers of the Eastern Han Dynasty,China. Asian Perspectives. 2016;54(2):238-52.

36. Yang YS, Shi NY, Shi ZL. Archaeological discovery and study of the bi-directional communication of agriculture in prehistoric Hexi Corridor (in Chinese),. Journal of Dunhuang Studies. 2016;1:82-91. 37. Shen ZZ. Crops in the Han Dynasty (in Chinese),. Agricultural History of China. 1998;1:104-6.

38. Dong G, Yang Y, Han J, Wang H, Chen F. Exploring the history of cultural exchange in prehistoric Eurasia from the perspectives of crop diffusion and consumption. Science China Earth Sciences. 2017;60(6):1110-23. doi: 10.1007/s11430-016-9037-x.

39. Li C. Wheat cultivation and popularization in the Yellow River basin from prehistory to Han Dynasty (in Chinese with English abstract). Northwest University; 2014.

40. Haaland R. Porridge and Pot, Bread and Oven: Food Ways and Symbolism in Africa and the Near East from the Neolithic to the Present. Cambridge Archaeological Journal. 2007;17(2):165-82. doi: $10.1017 /$ S0959774307000236.

41. Li X. The 'barbecue' custom in the Han Dynasty based on archaeological materials (in Chinese). Sichuan Cultural Relics. 2016;1:77-81.

42. HPM. Hubei Provincial Museum, The Tomb of Zeng Houyi in Sui County (in Chinese). Beijing: Cultural Relics Press; 1980.

43. GMACR, IACASS. (Guangzhou Municipal Administration of Cultural Relics), (Institute of Archaeology Chinese Academy of Social Sciences), Guangdong Museum, The Nanyue King Mausoleum of the Western Han Dynasty (in Chinese). Beijing: Cultural Relics Press; 1991.

44. Yang F. Social economy development of Ningxia in Han Dynasty based on archaeological materials (in Chinese with English abstract). Journal of Yunnan Finance and Trade Institute, . 2011;27(6):149-54. 45. Yao WL. Tombs in the Han Dynasty (in Chinese). Archaeology and Cultural Relics. 2002;1:81-90. 


\section{Supplementary Files}

This is a list of supplementary files associated with this preprint. Click to download.

- SUPPLEMENTARYMATERIALTableS1.docx 